\title{
Slim Physique Image for Female: Discovering its Socio-psychological Outcomes
}

\section{H. Ali (Humera Ali)', A. Gul (Ayesha Gul)², M. Yousaf (Mohammad Yousaf)3, R. Changezi (Rahim Changezi) ${ }^{4}, A$. Naz $\left(\right.$ Arab Naz) ${ }^{5}$}

1 M. Phil Scholar. Social Work Department. SBK Women's University

\section{Original Article} Quetta, Pakistan.

2 Assistant Professor. Social Work Department. SBK Women's University Quetta. Balochistan, Pakistan.

${ }^{3}$ Lecturer Social Work Department. University of Balochistan Quetta, Pakistan.

${ }^{4}$ Assistant Professor. Social Work Department. University of Balochistan Quetta, Pakistan.

5 Professor Sociology Department. University of Malakand. Khyberpakhtunkhwa, Pakistan.

\section{E-mail address:}

arab_naz@yahoo.com

\section{Reprint address:}

Arab Naz

Department of Sociology

University of Malakand

Khyber Pakhtunkhwa

Pakistan

Source: Clinical Social Work and Health Intervention

Volume: 10

Issue: 3

Pages: 7 - 14

Cited references: 11

\section{Reviewers:}

Vlastimil Kozon

Allgemeines Krankenhaus - Medizinischer Universitätscampus, Vienna, AT

Daniel J. West, Jr

University of Scranton, Department of Health Administration and Human Resources, USA

\section{Keywords:}

Body Image. Media. Globalization. Health Issues. Positive Body Image. Negative Image.

\section{Publisher:}

International Society of Applied Preventive Medicine i-gap

CSWHI 2019; 10(2): 7 - 14; DOI 10.22359/cswhi_10_3_01 (c) 2019 Clinical Social Work and Health Intervention 


\section{Abstract:}

Our world view is guided by the physical world, our knowledge, experiences and our perceptions and beliefs. While shaping our world view in the age of globalization, media through its presentations is one of the powerful elements. Body image is an important part of one's life, as having a positive body image can lead to a happier and satisfied life while a negative body image can lead to a damaging behavior. Media's effects on people particularly women have caused many problems such as on health, which has been a recent topic for many scholars. The discussion which is dominating is either it has positive effect such as obesity or its cause or its negative effect such as thin ideal bodies preferable for women. Further, this has created many social, emotional, psychological and health issues. This study is important in many ways especially in terms of disclosing those factors that influence women to adopt to an ideal body described in the media. There are researches conducted on the topic however; there are very limited amount of researches conducted in Pakistan especially in Balochistan. This study is unique in its nature because it reveals the health issues associated with negative body images.

\section{Introduction}

There is increasing concern about the negative impact of ultra-slim models commonly used in advertising on women's body satisfaction, as evidenced in the recent Journal of Social and Clinical Psychology special issue on body image. The body size of glamorous models is often more than 20\% underweight (Abbott, Barber, 2011). This widening gap between larger actual body sizes and the cultural obsession with an ultra-thin body size has been blamed for women's "normative" experience of body dissatisfaction, and it is this gap which is made salient to women every time they are exposed to thin ideals in the media. Yet, in contrast to the numerous demonstrations that exposure to ultra-thin media models has a negative effect on many women, there has been comparatively little systematic investigation of the moderators, the when and who, and even less of the mediators, the why and how, underlying this effect (Grogan, 2012).
Body Image is defined as the person's own judgment of their appearance and beauty. These words were first used by G. Gerbner, an Austrian neurologist and psychoanalyst. He mentioned about the perception of body image in his book on how people sense their own bodies and what people think their body should be (Gerbner, 1998). The understanding of an individual about their body image can differ from society's standard. However, ideals around it can affect a person's perception of their body image including socio-cultural influence; influence of media; peer appraisal. (Alexandra, 2013)

An individual's understanding of their body image affects their emotions, acknowledgment, and self-esteems (Alexandra, 2013). Body image perception can differ among gender groups as well as people from various ethnicities will have different perception of their body image. Body dissatisfaction was found to be more common 
and felt more intensely in women, though men were also clearly affected by body dissatisfaction (Alexandra, 2013). Several health disorders, including eating disorders, are more common among females as compared to males. The latter seem to be affected more by cultural norms and peer pressure. There are various causes that can be associated with negative body image perception that in return lead to certain changes in a person's performance and sometimes can be damaging. Some of the main factors that effects body image development are as follows:

\section{Influence Of Media On Body Image}

Media is regarded as the most influential element in shaping and influencing body image in today's world. In early childhood media inspires indirectly, as the child regards his/her parents, family members or teachers and societal members as their role model. These nominated people are directly affected by media in the case of body image. Media also effect body image directly, as the child grows to youngster. As it is the age of body consciousness media presents the role model for society and portrays it time and again. This direct contact with media influences an individual's body image and body perception directly and most of the time produces negative impact (Franko, Roehrig, 2011).

\section{Culture and Body Image}

Individuals have strong contacts with society. Prevailing culture of a society has deep impact on the development of body image. Culture sets the norm and value of beauty so these valuations of beauty influence body image. Culture may have both positive and negative impacts on body image which is subject to the nature of the society and its modes of production and interaction. Media is also associated with cultural values in the modern times. This study assesses to what extent cultural values are under the influence of media regarding body image (Abbott, Barber, 2011).

\section{Peer Pressure}

The word peer can be used as nobles or role models. Role models indirectly exert pressure on individuals as the individuals set their own role model through their exposures. Is it important how the individual set its role model? Is the process subjected to the influence of parents, family, culture or media? Most of the time in this modern word, role models are set under the instructions of media. Thus, peers may also have both negative and positive impacts on body image (Carlson, 2002).

\section{Other Psychological Stressors}

Psychological stress is a common phenomenon when the process of comparison begins. The exposure of individuals leads for setting role models that lead to the process of comparison. Individuals setting of role model is subjected to exposure. During exposure the individual gets inspired by someone's personality, workings, position or any other characteristic. In the case of inspiration, the individual is subjected to follow the set role model. While following the role model the individual intentionally or unintentionally compares his/herself to the role model. With a process of comparison in any way leads to the physical comparison, which ultimately influences body image of the individual. Most of the time it produces negative impact on body image and directly leads to psychological stress (Breitkop, Littleton, Berenson, 2007).

\section{Literature Review}

When women are asked directly how exposure to images of slim women affects them they tend to respond negatively. However, when the self-report questions are less obviously connected to the slim body images, women are more likely to be positive 
or self-enhancing pattern-controlled eaters. They are more concerned with their size and shape and thus are more devoted to comparing themselves with slim models. Because exposure to the images was incidental to

the alleged purpose of the study, the Research has shown that the need to achieve physical attractiveness puts considerable pressures on female.

The effect of slimness-promoting media has been the statement that all women return to slim-body images in the same way. Individual differences that may moderate the relation between media exposure and body image are often ignored (Botta, 1999); for example, that body displeasure as a result of encountering slim-body images should be confined to those who approve the slim ideal. A recent series of studies supports the idea that not everyone reacts to slim-body images in the same way. In fact, some women feel better about their appearance after looking at slim women.

Unrealistic media images of leanness also present ideals that appear to be achievable to the average woman, and that these images promote the misunderstanding that the slim woman body size represents the standard body weight that women should try to rival. One of the societal causes of this cultural concern is the media and the ultra-slim standards the media represent as the ideal, feminine body image. These images are presented to females during the entireness of their lifetimes. This continuous experience to idealistic, female body ideals can promote body displeasure, which can contribute to depression, and ultimately, eating disorders. The researchers found that beauty is the core feature of femininity as portrayed by the media and the core factor in the attractiveness stereotype of women.
Social values about women and beauty promote a risk factor for developing an eating disorder. Social pressure to be slim is practiced by many women and young girls. Women and their beauty have been found that overweight girls and women experience significant social pressure, as well as including teasing about weight, perception, and blame. The slim ideal body has been constructed by society and by the media and women and girls is expected to conform to it (Striegel-Moore and Smolak, 2000).

Cultural messages that idealize slim woman body images promote an increase in weight concerns in women. The slim female body image as the societal standard for women prompts girls to view physical appearance as a vital element in cultivating their positive self-esteem (King and Tsiantas 2001).

Development of body image is a lifetime process. The experiences that we have and the feedback that we receive about our bodies from other members of society influence the way we perceive our bodies. These experiences and emotions we receive as children and adolescents about our appearance have an important impact on the formation of our body images. According to researchers, since 1959 the societal standard for the ideal, female body image has increasingly promoted slimness (King and Tsiantas, 2001).

\section{Research Objectives}

1. To analyze the slim or lean Ideal body image.

2. To explore the social effects of slim body on women's confidence and self-esteem.

3. To identify the psychological effect of body images on women. 


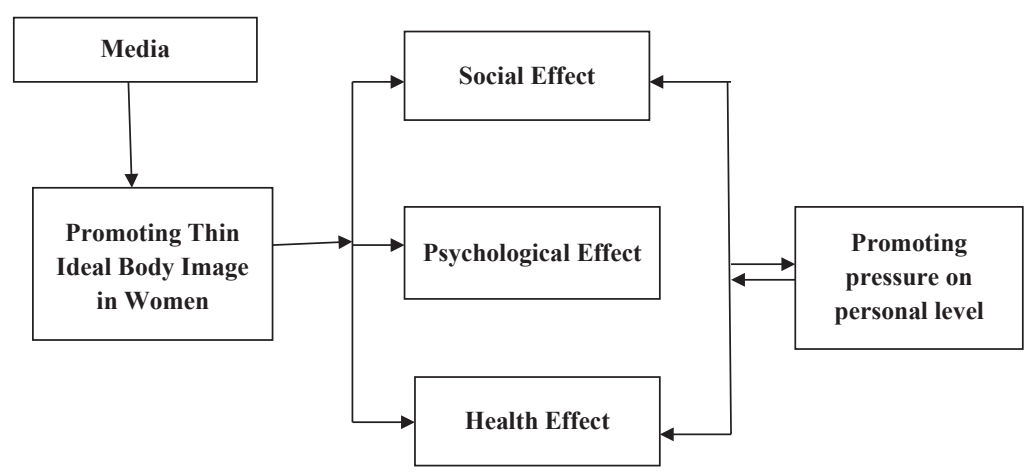

\section{Conceptual Framework}

Our world view is guided by the physical world, our knowledge, experiences and our perceptions and beliefs. Media is one of the powerful elements while shaping our world view in the age of globalization, through its presentations. Today's media is promoting thin ideal body image which in most of the cases has negative impact on individual body image, especially for women. Beside this media is also influencing the cultural values regarding body image, that ultimately exerting pressure on individual.

However, with the promotion of the thin ideals media is affecting women psychologically, socially, and also their health. The role of media and its impacts on women are being discussed in the coming parts of this research.

\section{Research Methodology}

This part of the study discloses the procedure of selecting simple themes for the study; an explanation of the themes involved in the research; the composition of the measuring instrument used in the study. This research is qualitative in nature. For this reason a theoretical framework is developed with the help of established theories which were already discussed in a previous part of this study. In first instance this part of the study explains the research design for this study.

\section{Research Design/Universe and Sampling:}

Research design enables researchers to study any phenomena in a proper way. The nature of this study is qualitative, so qualitative research was being used as a research design. To complete this study in a proper way, I opted for the development of a unique research design based on previous research techniques. For this purpose a self-originated framework was designed with the help of theories, questioners and a study guide for focal group discussions. The research design of the current study is guided by previous research done in different parts of the world, including selected universe of the study; measurement tools; the process of data collection.

For maximum information, the research opted to select educated females in the society of Balochistan. Researcher therefore opted to select the main city of Balochistan, Quetta which is the junction of all cultural values and ethnicities of the province. 15 female respondents of three main universities were taken as the universe of the study. Three of the main public sector universities were selected as the universe of this research for the collection of data. These are University of Balochistan (UoB), Balochistan University of information technology and Management Sciences (BUITMS) and Sardar Bahadur Khan Women's University (SBK). 
A purposive sampling is being used for selection of the true representation of the universe. Purposive sampling is the sampling tool which is used in qualitative research for the selection of respondents in a universe. In this sampling, the researcher selected respondents who are more related with the research topic and conveniently available.

This non-probability research is used for abetter understanding and analysing of data with the help of the thematic analysis method. In the analysis of the data, the researcher subjected the collected information to the theoretical aspects of the study.

\section{Results And Discussions}

The information revealed in this study is in accordance established by the previous chapters of this research. These findings are given below.

The demographic information revealed that body image is affected by the ethnic origin of individual and it differs from one place to another. In short body image is associated to ethnicity and place in Balochistan subjected to the nature of geography and climate.

The study revealed that as in other parts of the world women's body image is effected by: media, peers, parents and family and culture.

Parental influence produces both positive and negative impacts on girl's body image. In rural areas parental influence produces positive impacts due to encouragement of stronger body culture while in urbanized society parent's influences girls to follow their slim attitudes which negatively affect girl's body image.

There exists a complex relation; regarding women's body image among Media, Peers and Cultural values in the society of Balochistan.

The cultural values in Balochistan are inspired by media and show convergence to the media's propagated slim body image.

The cultural values again shows dual impacts on women body image. Those exposed to media produced negative impacts on women's body image, while the values which are not exposed to media produces positive impacts on body image.

Peer's response toward women's body look is under the influence of both cultural values and media, which produced negative impacts on girl's body image.

Media is regarded as the most influential factor regarding body image as it shapes parental, family and peer perceptions regarding body image which ultimately shape cultural values of society.

Exposition of women to media produces negative impacts on girl's body image. Media is propagating the ideals of slim body in unhealthy ways, resulting negative body image.

The negative impacts of the influencing factors of slim ideal body image produces negative impacts on women's confidence and self-esteem. These negative impacts produce different health issue for women.

Eating disorders are one of the major health problems that are caused by negative impacts of body image include anorexia nervosa, bulimia nervosa and compulsive overeating.

Distorted body image which includes body dysmorphic disorder and depression, is also caused by negative impacts of body image.

The negative impacts of body image also caused psychological problems for women in Balochistan.

The above findings are the main explorations of this research which allows discussion in light of the literature.

One of the respondents said:

“Today's media is powerful as it also affects the lives and ways of living of our cultural elite. Once media inspires elite culture, these cultural values are being fol- 
lowed by the common people either in connection with media or with cultural elite."

Another female said:

"Without any doubt Media is a most effective element for propagation of ideals of slim body. Our parents are inspired by the values set by media

and forcing us to follow these ideals. Women's dress and lifestyle are also dominated by the propagated values of media, which ultimately shape our cultural values, which in return inspires peers and families. Thus it is media that is the root factor regarding the ideals of the slim body."

She added that:

"Before connection with media I had no idea of beauty but by reading the fashion magazines I got the idea regarding looking beautiful".

"Our society is inspired by media and our cultural values are dominated by men in all respects. Thus the wishes of men are being accepted in our society without reason. Men are inspired by media whom opted slim body as values of beauty that is why they are looking for thin and slim bodies regardless of their skills".

She further narrated that:

"She always tried to look like her. Here it is important that she is comparing herself with her peer and she is being influenced by peers with negative results."

The Focus Group Discussion verified through the respondent's statement:

"I always remain worried regarding my height and weight when I appeared in any gathering or passing people in my way". She further added that "due to concern of weight I always try to avoid public gathering and even sometimes special occasions like marriages and other cultural tasks".

\section{Conclusion}

Body Image can be defined as the person's own judgment of their appearance and beauty. Body image comprises how people sense their own bodies and what people think their bodies should be or look like. An individual's understanding about their body image can differ from society's standard. However, the environment itself can affect a person's perception of their body image including socio-cultural influence, influence of media and peer appraisal.

This study concludes that under peer pressure selected through exposure of media, cultural values (adopted under the propagated ideals of media), family and media had affected women's self-esteem negatively. The media's portrayal of thinness as a standard of female attractiveness is thought to play a determining role in women's contentious relationship with their bodies by pressuring them to lose weight and be thin.

Including eating disorders, Body Dimorphic Disorder (BDD), body image, a person's perceptions, thoughts, and feelings about his or her body, are not limited to the visual characteristics of the person, but also take into consideration his or her state of health, skills, and sexuality.

However, the study summarizes that women's body image is affected by peers, family, cultural values and media. The impacting factors producing negative body image led to different body issues that include: body disorder, eating disorder, psychological problems and negative self-esteem. For these reasons this research recommends the following steps to be taken.

\section{Recommendations}

Like other parts of the world, research studies must be conducted to further investigate the issue of negative body image and its associates in Balochistan.

Parental influence produces both positive and negative impacts on girl's body image. Parents must be guided regarding the positive side of the fuller body and its benefits, 
so as to produce positive impacts on girl's body image.

The cultural values in Balochistan are inspired by media and show convergence to the media's propagated slim body image. Thus is important to propagate positive impacts of the old existing fuller women's body to sustain a positivity of the culture regarding women's body image.

Media in Balochistan is required to project the prevailing body image of the rural areas of Balochistan, in order to provide space for the culture and to counter the ultra slim ideals of women's body image.

Peer response toward women's body look is under the influence of both cultural values and media which produce negative impacts on girl's body image. Thus family, cultural values and media are required to help children to acceptance of peers with fuller bodies.

Media is regarded as the most influential factor regarding body image as it shapes parental, family and peer perceptions regarding body image which ultimately shape cultural values of the society. Thus media is required to project fuller body images of women and counter ultra-slim ideals of women's body image.

\section{References}

1. ABBOTT B D, BARBER B L (2011) Differences in functional and aesthetic body image between sedentary girls and girls involved in sports and physical activity: Does sport type make a difference? Psychology of Sport \& Exercise, 12(3), 333-342.
2. BOTTA R A (1999) Television images and adolescent girls' body image disturbance. Journal of Communication, 49(2), 22-41.

3. BREITKOP C, LITTLETON H, BERENSON A (2007) Body Image: A Study in a Tri-Ethnic Sample of Low Income Women. Sex Roles, 56(5/6), 373-380.

4. FRANKO D L, ROEHRIG J P (2011) African American Body Images, Body Image: A Hand-book of Science, Practice, and Prevention, (New York: Guilford Press,), pp. 221-228.

5. GERBNER G (1998) Cultivation analysis: An overview. Mass Communication \& Society, 1(3/4), p. 180.175-194.

6. GROGAN S (2012) Body Image Development in Adulthood, Body Image: A Handbook of Science, Practice, and Prevention, (New York: Guilford Press, 2011), pp. 93100.

7. HOWSON A (2013) The Body in Society: An Introduction. Cambridge: Polity Press.

8. JONES D C (2002) Social Comparison and Body Image: Attractiveness Comparisons to Models and Peers among Adolescent Girls and Boys. Sex Roles, Nov 2001, Vol. 45, Issue 9/10, 645-664.

9. GROGAN S (2008) Body Image: Understanding Body Dissatisfaction in Men, Women, and Children, (New York: Routledge), p. 3.

10. STRIEGEL-MOORE R H, SMOLAK L (2000) The influence of ethnicity on eating disorders in women.

11. TSIANTAS G, KING R M (2001) Similarities in body image in sisters: The role of sociocultural internalization and social comparison. Eating Disorders, 9(2), 141-158. 